\title{
Práticas docentes inclusivas para alunos com deficiência intelectual em contextos escolares
}

\author{
Inclusive teaching practices for students with intellectual \\ disabilities in school contexts
}

\section{Prácticas de enseñanza inclusivas para estudiantes con discapacidad intelectual en contextos escolares}

\author{
Maria Socorro Santos Leal Paixão ${ }^{1}$ \\ ORCID: http://orcid.org/0000-0001-6783-2707
}

Ana Valéria Marques Fortes Lustosa ${ }^{2}$

ORCID: http://orcid.org/0000-0002-3540-9952

\begin{abstract}
Resumo: Este estudo teve como objetivo geral investigar as práticas docentes de professores para alunos com deficiência intelectual na escola regular. Trata-se de uma pesquisa de cunho qualitativo, com delineamento da pesquisa-ação. O estudo foi realizado em duas escolas públicas da rede municipal de Teresina (PI) e desenvolvido mediante a participação de seis professoras dos anos iniciais do ensino fundamental que atuavam na classe comum. Foram utilizados como procedimentos metodológicos o diagnóstico dos conhecimentos prévios das professoras, as sessões de estudo denominadas encontros de estudo e a observação. Para a produção das informações, utilizamos a estratégia "casos de ensino" e, como instrumentos, o questionário e o diário de campo. Os resultados evidenciaram que as professoras não conseguiam organizar e implementar práticas diferenciadas da proposta curricular do ano escolar que o aluno com deficiência intelectua estava frequentando. Elas utilizavam com esses alunos atividades distanciadas do currículo da turma, que eram mais simples e mais fáceis. A falta de formação específica para trabalhar com alunos PAEE foi o
\end{abstract}

1 Graduada em Pedagogia pela Universidade Federal do Piauí. Pós-graduada em Orientação Educacional (PUC/MG). Mestre em Educação pela Universidade Federal do Piauí . Doutora em Educação pela Universidade Federal do Piauí. Professora da Universidade Federal do Piauí, com atuação na área de Fundamentos Psicológicos da Educação. Tem experiência na área de Psicologia da Educação, com ênfase em Ensino e Aprendizagem na Sala de Aula, atuando principalmente nos seguintes temas: educação inclusiva e deficiência intelectual.

2 Graduada em Psicologia pelo Centro Universitário de Brasília (1990). Mestre em Educação pela Universidade Federal do Piauí (1998). Doutora em Psicologia pela Universidade de Brasília (2004). Pós-doutorada em Educação Especial pela Universidade Federal de São Carlos. Atualmente é professora associada IV da Universidade Federal do Piauí e coordenadora do Núcleo de Estudos em Educação Especial e Inclusiva NEESPI. 
elemento que mais se destacou como dificuldade, na fala das professoras, realçado pelo sentimento de despreparo para o trabalho.

Palavras-chave: Prática docente. Inclusão escolar. Deficiência intelectual.

Abstract: This study had as a general objective to investigate the teaching practices of teachers whose students have intellectual disability in regular school. It is a research of qualitative nature with delineation of the action research. The study was carried out in two public schools from the Municipal Network in Teresina (PI) and developed with six participants, tearchers from early years of elementary school who worked in the common class. As methodological procedures, it was used the diagnosis of the previous knowledge of the teachers; study sessions denominated study meetings; and observation. For information production, we have used the strategy teaching cases and, as tools, the questionnaire and the field diary. The results highlighted that the teachers could not organize and implement differentiated practices from the curricular proposal of the school year when the student was attending. They used activities distanced from the class' curriculum which were simpler and easier with students with intellectual disability. The lack of specific training to work with students from Target Group Students in Especial Education (PAEE) was the most highlighted element as a difficulty in the comment of the teachers, outlined by the feeling of unpreparedness for work.

Keywords: Teaching practice. School inclusion. Intellectual disability.

Resumen: Este estudio tuvo como objetivo investigar las prácticas de enseñanza de los profesores de alumnos con discapacidad intelectual en la escuela regular. Se trata de una investigación cualitativa, con delineamiento de investigación-acción. El estudio se realizó en dos escuelas públicas de la red municipal de Teresina (PI) y se desarrolló con seis participantes, maestros de los años iniciales de la escuela primaria, que actuaban en la clase común. Se utilizaron procedimientos metodológicos diagnóstico de los conocimientos previos de las maestras; sesiones de estudio denominadas encuentros de estudio; y observación. Para la producción de las informaciones, utilizamos la estrategia casos de enseñanza y, como instrumentos, el cuestionario y el diario de campo. Los resultados evidenciaron que las maestras no consiguieron organizar e implementar prácticas diferenciadas de la propuesta curricular del año escolar al que el alumno estaba frecuentando. Ellas usaban con estudiantes con discapacidades intelectuales, actividades alejadas del currículo de la clase, que eran más simples y fáciles. La falta de formación específica para trabajar con alumnos PAEE fue el elemento que más se destacó como dificultad, en el discurso de las maestras, resaltado por el sentimiento de falta de preparación para el trabajo.

Palabras clave: Práctica docente. Inclusión escolar. Discapacidad intelectual.

\section{INTRODUÇÃO}

O direito das pessoas com deficiência à educação foi ignorado por muito tempo em função de questões relacionadas a crenças, aliadas ao preconceito e à concepção de deficiência como condição imutável, de forma que tais crenças foram responsáveis pela omissão da sociedade quanto à necessidade de atendimento educacional a pessoas deficientes, levando-as à marginalização (MAZZOTA, 1996).

A história da escolarização dos alunos público-alvo da educação especial ${ }^{3}$ (PAEE) mostra uma trajetória marcada pela exclusão e, durante muito tempo, o acesso à educação

3 Público-alvo da educação especial é a terminologia adotada atualmente nos documentos legais no Brasil para se referir aos alunos com deficiência, com transtornos globais do desenvolvimento e com altas habilidades/superdotação. Aparece especificamente na Lei Brasileira de Inclusão de 2015. 
por esse segmento se deu em instituições especializadas e, ainda assim, para um número reduzido, configurando-se como um sistema paralelo de ensino, voltado prioritariamente para o atendimento terapêutico. Ressalta-se, mais uma vez, que a grande maioria não tinha acesso sequer a esse atendimento.

A recente inserção na escola regular de alunos com desenvolvimento atípico, assegurada pela política de inclusão, alterou significativamente a dinâmica dessa instituição e teve forte impacto sobre o professor, tanto no âmbito pessoal, quanto no profissional. Em geral, a presença desses alunos na escola regular não é aceita com naturalidade pelos agentes educativos, especialmente pelo professor que está diretamente em contato com eles, muitas vezes, sem saber como proceder (BRAUN, 2012; SANTOS, 2010).

No contexto da educação inclusiva, a escola deve criar condições para que todos os alunos aprendam e tenham sucesso em suas aprendizagens. São várias as mudanças que a escola precisa empreender para conseguir oferecer uma educação de qualidade, pois a inserção de todos os alunos na sala de aula comum requer uma revisão/reorientação do currículo, das metodologias e das práticas pedagógicas desenvolvidas na escola (PLETSCH, 2009; MOSCARDINI, 2011; SANTOS, 2012).

É importante destacar que ainda são escassos os estudos sobre práticas pedagógicas com alunos com deficiência intelectual em sala de aula comum. Consideramos que esse campo precisa ser investigado em maior profundidade para que se esclareça o que vem acontecendo com os alunos que têm essa condição e que se encontram matriculados na escola regular. É oportuno sobrelevar que, no estado do Piauí, estudos sobre essa temática são ainda mais escassos e a realidade exige propostas teóricas e práticas que possam subsidiar o trabalho realizado pelos professores da educação básica com esse público.

Assim, o interesse pela compreensão da prática docente de professores de alunos com deficiência intelectual fundamenta esta pesquisa, que procura responder à seguinte questão: Quais as práticas docentes adotadas por professores de alunos com deficiência intelectual na escola regular com vistas à inclusão?

Em decorrência dessa problemática, o estudo teve como objetivo geral investigar as práticas docentes de professores de alunos com deficiência intelectual na escola regular. Para alcançar a contento este objetivo geral, foram definidos os seguintes objetivos específicos: caracterizar e analisar as práticas docentes de professores de alunos com deficiência intelectual e identificar dificuldades presentes na prática de professores desses alunos.

A prática docente está sendo entendida como o fazer do professor, o conjunto de ações conscientes e intencionalmente por ele planejadas e executadas em sala de aula, conectadas com as demais práticas que se realizam na escola, com vistas à aprendizagem do aluno, ou seja, tudo aquilo que configura sua atuação pedagógica e está diretamente 
relacionado ao processo de ensino que, por sua vez, não se desvincula do processo de aprendizagem (FRANCO, 2012; SOUZA, 2012; TACCA, 2006).

\section{REFERENCIAL TEÓRICO}

Por determinação legal, as pessoas com deficiência, dentre as quais as que apresentam Deficiência Intelectual (DI), conquistaram o direito de acesso ao sistema formal de educação. No Brasil, desde a década de 1990, estamos convivendo com a presença desses alunos nas classes regulares de ensino, porém, há indicadores de que os alunos com DI não estão se apropriando dos saberes escolares, de modo que a aprendizagem desses alunos não tem sido favorecida pela escola (CHINALIA, 2014; PLETSCH, 2014; MENDES, 1995).

Há sempre muita discussão em torno do fenômeno, por muito tempo, conhecido como deficiência mental ${ }^{4}$. Por se tratar de um conceito amplo, de interesse de vários profissionais e passível de várias definições, ele tem suscitado muitas controvérsias que refletem, em parte, o desconhecimento que a sociedade tem em relação a essa deficiência. $A$ nomenclatura deficiente mental tem sua origem no Congresso de Genebra, realizado em 1939, e foi apresentada para substituir o termo anormal e, ao mesmo tempo, serviu para a padronização mundial da referência (CARNEIRO, 2006). Desde então, muitos debates em torno da questão foram desencadeados, apontando a carga negativa e a visão estigmatizante que o termo carrega.

Em 1992, a Associação Americana de Retardo Mental — American Association Mental Retardation (AAMR) - definiu a deficiência intelectual como um comprometimento que se manifesta antes dos 18 anos e que se caracteriza por um funcionamento intelectual abaixo da média e por dificuldades adaptativas. Vale ressaltar que essa Associação mudou de nome a partir de 2001, passando a chamar-se Associação Americana sobre Deficiências Intelectuais e do Desenvolvimento - American Association Intellectual and Developmental Disabilities (AAIDD) (COSTA, 2011).

O Brasil adotou uma definição de DI tendo como referência a proposta pela AAIDD, de modo que, na Política Nacional de Educação Especial de 1994, essa deficiência encontrava-se definida nos mesmos termos. O Decreto $n^{\circ} 5.296$, de 2 de dezembro de 2004, que regulamentou as Leis $n^{\circ} 10.048 / 2000$ e $n^{\circ} 10.098 / 2000$, traz a seguinte definição:

Deficiência Mental: funcionamento intelectual significativamente inferior à média, com manifestação antes dos dezoito anos e limitações associadas a duas ou mais áreas de habilidades adaptativas, tais como: 1. comunicação; 2. cuidado pessoal; 3 .

4 Esse termo foi utilizado por muito tempo, tendo sido alterado para deficiência intelectual em 2004, na Conferência de Montreal, Canadá, com a justificativa de que o problema afeta somente o intelecto e não a mente como um todo. 
habilidades sociais; 4. utilização dos recursos da comunidade; 5 . saúde e segurança; 6. habilidades acadêmicas; 7. lazer; e 8. Trabalho (BRASIL, 2004) ${ }^{5}$.

Para esclarecimento e melhor compreensão da questão, é preciso registrar que, em 2006, foi aprovada a mudança do termo deficiência mental para deficiência intelectual, motivada pelo avanço do conhecimento nas diversas áreas sobre o fenômeno do déficit intelectual, conduzindo os profissionais ao entendimento "de que o déficit cognitivo não está na mente como um todo e sim numa parte dela, o intelecto" (SASSAKI, 20076).

A despeito das várias interpretações que circulam sobre a deficiência, dois modelos antagônicos na explicação do fenômeno se destacaram: o biológico e o social. O primeiro foi hegemônico por muito tempo e influenciou o diagnóstico e as práticas educacionais destinadas aos indivíduos com deficiência, de tal modo que sua hegemonia se faz sentir até hoje. O modelo biológico alicerçou-se em saberes provenientes das Ciências da Saúde e ficou conhecido no mundo ocidental, na década de 1960, postulando que a deficiência é uma patologia individual e, portanto, a responsabilidade pela condição é da pessoa ou da sua família (PICCOLO; MENDES, 2012).

O modelo biológico, por bastante tempo, orientou o diagnóstico da deficiência intelectual, baseado exclusivamente nos níveis de quociente intelectual (QI), a partir do qual as pessoas eram classificadas, conforme o grau da deficiência apresentada (leve, moderada, severa e profunda), e definidas, levando em conta as perspectivas de aprendizagem. A deficiência era compreendida como um traço pessoal, inalterável. Esse diagnóstico centrado no modelo médico contribuiu para fortalecer a discriminação contra as pessoas que apresentam algum problema no funcionamento intelectual, como algo centrado no sujeito, desconsiderando todos os fatores sociais e culturais que podem determinar a situação.

O surgimento das instituições filantrópicas, sem dúvida, constituiu uma contribuição relevante ao se apresentar como alternativa de atendimento àqueles alunos excluídos da escola regular por serem considerados incapazes de aprender. Não obstante esse papel importante, essas instituições foram alvo de muitas críticas por seu caráter segregador.

As classes especiais, implantadas no final da década de 1970 nas escolas regulares, para atender alunos classificados com DI leve, no período que ficou conhecido como paradigma da integração, constituem um exemplo da legitimação de um espaço de segregação por ter contribuído com a seletividade social praticada por essas escolas, absorvendo alunos, em sua maioria de classes socialmente menos favorecidas, apontados como apresentando déficits de aprendizagem.

A avaliação realizada nesses moldes foi responsável por um número excessivo de crianças com rótulo de DI, apontando confusão entre esta e as dificuldades de aprendiza-

5 Disponível em: <http://www.planalto.gov.br/ccivil_03/_ato2004-2006/2004/decreto/d5296.html>. Acesso em: 04 jan. 2021.

6 Disponível em: <https://acervo.plannetaeducacao.com.br/portal/artigo.asp?artigo=1320>. Acesso em: 04 jan. 2021. 
gem. Como consequência, encontra-se, nesse período, um número elevado de crianças encaminhadas para a classe especial no início da escolarização, com histórico de dificuldade na aprendizagem da leitura e da escrita. Por essa razão, a categoria de alunos com DI apresenta-se extremamente ampla, incluindo também aqueles alunos que apresentam dificuldades de aprendizagem e problemas de comportamento (MENDES, 1995).

A avaliação e identificação do aluno com deficiência intelectual sempre foi e continua sendo uma questão complexa. Estudos apontam (VELTRONE, 2011) que é o grupo mais numeroso, concentrando cerca de $50 \%$ de todos os alunos PAEE matriculados, o que pode sugerir que a identificação não é precisa. Entretanto, se considerarmos as matrículas de alunos com DI no Brasil, essa proporção pode chegar a 70\%. A complexidade do conceito e dos critérios pode ensejar práticas de identificação arbitrárias e subjetivas. "Além de ser o maior contingente do alunado, o fato do déficit ser de natureza cognitiva faz com que esses alunos - que são o PAEE, sejam os maiores causadores de dúvidas e desafios no espaço educacional" (MENDES; TANNUS- VALADÃO; MILANESI, 2016, p. 51).

Como alternativa ao modelo médico, surge na Inglaterra, no fim dos anos 1970 , através do grupo Desabilite Studies, o modelo social da deficiência, pressupondo "que as pessoas com deficiência são sistematicamente discriminadas e excluídas da participação na sociedade contemporânea, sendo esse o resultado negativo das barreiras atitudinais, físicas e institucionais que estabelecem tal limite às pessoas com impedimentos corporais" (GESSER; NUERNBERG; TONELI, 2012, p. 559). Para esse modelo, a deficiência não é uma condição inerente ao indivíduo, mas consequência da organização social. Vê-se, pois, que o problema da deficiência é deslocado do indivíduo, como defende o modelo médico, para a sociedade, conforme esclarece Piccolo (2015, p. 89):

[...] É a estrutura social que desabilita e cria a deficiência devido à falta de serviços e oportunidades adequadas para assegurar a plena e incondicional inclusão social de todos. Partindo desse esteio teórico, é a sociedade que deve se adaptar e acomodar para locupletar as necessidades de seus membros e não o contrário. A deficiência não é uma consequência natural do corpo lesionado, e sim uma imposição social relacionada a não adaptação da diferença [...].

Na base da explicação oferecida pelo modelo social está a compreensão de que muios problemas enfrentados pelas pessoas com deficiência não se devem a características intrínsecas ao indivíduo, em função de sua deficiência, pois esta não pode ser vista como um prejuízo, já que é a manifestação da diversidade humana. Ao contrário, os problemas evidenciam a inadequação do ambiente, a falta de acessibilidade, o desprezo da sociedade pelas necessidades das pessoas com deficiência que se veem excluídas dos espaços sociais e, por extensão, da educação, do trabalho, do lazer. Nesse sentido, o modelo social advoga a necessidade da mudança social e os seus formuladores defendem 
"[...] a concepção de que a mudança do ambiente e das relações sociais altera o significado e sentido que a deficiência desempenha na sociedade" (PICCOLO, 2015, p. 119).

A categoria deficiência intelectual é bastante genérica, pois nela estão incluídas pessoas com problemas e necessidades muito diversificadas (MENDES, 1995). Assim, enquanto construto científico, o conceito de deficiência intelectual tem sofrido muitas mudanças ao longo do tempo, de modo que, sobre a definição atual, podemos afirmar que:

[...] o termo é um amplo guarda-chuva que abriga indivíduos que pelos mais variados motivos não conseguem atender as exigências sociais, e que por razões pragmáticas têm sido agrupados arbitrariamente numa mesma condição. [...] Em decorrência disto, o campo se defronta com problemas aparentemente insolúveis e com uma compreensão ainda incompleta do que é a DI, e que induzem a divergências teóricas e dificuldades para se estabelecer conclusões sobre qual é a meIhor forma de educar esses indivíduos (MENDES; TANNUS-VALADÃO; MILANESI, 2016, p. 6).

Um longo percurso marca a história da escolarização dos educandos com DI. Mesmo sob a égide do paradigma da integração, os alunos com deficiência intelectual continuaram submetidos a práticas segregacionistas, frequentando as classes especiais. A partir da década de 1990, quando tem início a implementação do paradigma da inclusão, esses alunos passaram a ser matriculados nas classes comuns das escolas regulares, muito embora esse movimento não tenha representado grande avanço na sua escolarização.

Desde então, muitos pesquisadores têm se interessado em investigar como esses sujeitos estão situados nesse contexto, que esforços têm sido mobilizados para garantir a sua aprendizagem (ROCHA; ÁVILA, 2015, PLETSCH; GLAT, 2012, GUADAGNINI; DUARTE, 2013). Todos se voltam para a análise de algum aspecto relacionado aos processos de ensino e aprendizagem de alunos com DI, apontando as dificuldades que as instituições de ensino demonstram ao ensiná-los.

Os educadores acreditam que, por suas dificuldades cognitivas, esses alunos são lentos, têm muita dificuldade com abstrações e, assim, durante o processo escolar disponibilizam menos conteúdos e mais simplificados (FERREIRA, 2007). Essa situação tem se concretizado na não alfabetização do aluno com DI.

Vários termos são utilizados para se referir ao trabalho docente. Prática educativa, práxis, prática pedagógica e prática docente são alguns dos termos que comumente aparecem na literatura, muitas vezes usados como sinônimos, acarretando dificuldade para quem lida com essa temática. Franco (2012) procura elucidar os distintos conceitos de prática, mostrando que não constituem práticas unívocas, porquanto são mutuamente articuladas, mas distintas por suas especificidades. Assim, a autora enriquece o debate com a seguinte afirmação: "Ao falarmos de práticas educativas, estamos referindo-nos a práticas que ocorrem para a concretização de processos educacionais. Já ao falarmos de práticas 
pedagógicas, estamos referindo-nos a práticas sociais exercidas com a finalidade de concretizar processos pedagógicos" (op. cit., p. 152).

Explicitando a relação entre prática pedagógica e prática docente, a autora esclarece que nem sempre a prática docente é prática pedagógica. Ela acredita que para isso acontecer é necessário que a prática docente seja intencional, isto é, que o professor tenha consciência do sentido da sua ação para a formação dos seus alunos. Assim, a prática docente e a prática pedagógica estão interligadas, mas, quando nos referimos à prática docente, estamos falando da "[...] ação específica do professor no interior da sala de aula que organiza formas e conteúdos para os alunos se apropriarem de determinados conhecimentos e saberes resultantes de várias práticas e de várias instituições, sendo na atualidade uma das fortes, a escola" (LIMA; SERGIO; SOUZA, 2012).

No centro da discussão sobre a implementação de uma proposta inclusiva que assegure práticas docentes para o ensino e a aprendizagem dos alunos PAEE, estudos recentes focalizam a necessidade de se discutir a acessibilidade ao currículo (GOULART, 2014; RODRIGUES et al, 2014; GARCIA, 2007; DORZIAT, 2007). Há por parte dos pesquisadores, apesar de alguma eventual divergência conceitual, o entendimento de que a flexibilização do currículo é condição essencial para que todos os alunos tenham acesso ao conhecimento.

Um discurso muito presente quando falamos sobre inclusão escolar de alunos PAEE é o de que o professor que se depara com esses alunos em sala de aula precisa adotar uma prática pedagógica que contemple a flexibilização do ensino, promovendo ajustes curriculares para eles a fim de que possam ter acesso ao currículo escolar, sob a justificativa de que esses não conseguem aprender com as mesmas estratégias adotadas para os demais. O professor da classe comum depara-se com termos como "[...] adaptações curriculares, acomodações do ensino, adequações curriculares individualizadas, flexibilização curricular, entre outros [...]" (ZERBATO; MENDES, 2018), que dizem respeito a como deve ser a prática pedagógica em salas inclusivas.

Consideramos que essas práticas são inviáveis, pois, ao focar no aluno e prever diferenciações individuais, estas acarretam mais trabalho para o professor, que terá essa demanda tanto no planejamento quanto na execução do ensino. Ao contrário, em contextos inclusivos, com classes heterogêneas, será mais benéfico o professor da classe comum adotar estratégias que ampliem a participação e a aprendizagem de todos os alunos (ZERBATO; MENDES, 2018; PLETSCH; SOUZA; ORLEANS, 2017).

Uma realidade da qual não podemos fugir é a de que a diversidade está presente nas salas de aula, uma vez que os estudantes têm características distintas, bem como interesses e preferências diversos, não sendo razoável que adotemos um único currículo para todos. Desse modo, o debate sobre como ensinar em classes inclusivas vem se fortalecendo e dele emergem abordagens como o Desenho Universal para a Aprendizagem (DUA), o Ensino Diferenciado e o Ensino Multinível de Resposta à Diversidade, que focalizam 
estratégias de ensino para todos os alunos. O trabalho pedagógico com alunos do PAEE também tem sido realizado na perspectiva do Ensino Colaborativo ou Coensino.

O conceito de DUA surgiu nos Estados Unidos em 1999, desenvolvido por David Rose e Anne Meyer, no esforço para produzir práticas pedagógicas acessíveis a todos os alunos. Inicialmente foi desenvolvido, pela arquitetura, o conceito de Design Universal na projeção de prédios públicos acessíveis ao maior número de pessoas e, posteriormente, transposto para a educação, em relação ao processo de ensino e aprendizagem. Nesse caso, diz respeito à adoção de estratégias de ensino variadas para garantir o ensino de todos os alunos. Assim, podemos dizer que "o DUA consiste na elaboração de estratégias para acessibilidade de todos, tanto em termos físicos quanto em termos de serviços, produtos e soluções educacionais para que todos possam aprender sem barreiras" (ZERBATO; MENDES, 2018, p. 149).

No bojo das discussões em torno de práticas inclusivas, outra abordagem desponta ao lado do DUA, como é o caso do Ensino Diferenciado, que defende que por serem as salas de aulas constituídas por alunos com perfis diversificados, em termos de estilo e de ritmos de aprendizagem, os professores precisam diferenciar o ensino para assegurar a todos eles a oportunidade de aprendizagem. Se aceitamos que os interesses e necessidades dos alunos são bastante divergentes, ainda que tenham a mesma idade cronológica, nos colocamos o desafio de oferecer aos estudantes diferentes formas de aprendizagem, pois compreendemos que um "ensino de tamanho único" não serve para todos (TOMLINSON, 2008; HEACOX, 2006).

Ao diferenciar o ensino, o professor altera o ritmo, o nível ou o gênero da instrução que costuma adotar para atender as necessidades, os estilos ou interesses de cada aluno (HEACOX, 2006), de modo que o ensino diferenciado envolve conteúdo, processo e produto. Portanto, "uma sala de aula com ensino diferenciado proporciona diferentes formas de apreender conteúdos, processar ou entender diferentes ideias e desenvolver soluções de modo que cada aluno possa ter uma aprendizagem eficaz" (TOMLINSON, 2008, p. 13).

Outra abordagem apontada para fazer frente à diversidade de alunos é a proposta do ensino em multiníveis, uma estratégia que se refere "[...] ao planejamento e execução de um mesmo tema ou conteúdo em níveis diversos de aprendizagem de acordo com as expectativas dos alunos da classe. Envolve objetivos únicos em diferentes níveis e estratégias diversificadas" (ALMEIDA, 2012, p.77). Assim entendido, diferencia-se das atividades diversificadas, pois estas dizem respeito ao trabalho com diferentes temas ou conteúdos, nem sempre com um único objetivo, utilizando diversas estratégias metodológicas.

O ensino colaborativo ou coensino é um modelo que consiste na presença de dois professores na sala de aula, um do ensino comum e outro da Educação Especial, que atuam colaborativamente no planejamento, na execução e na avaliação do processo de ensino. 
Os alunos com DI, por suas particularidades, especialmente em relação ao funcionamento cognitivo, demandam práticas diferenciadas das utilizadas com os demais alunos, para que possam acessar o currículo geral. Entendemos que a organização curricular deverá ser a mesma, mas as estratégias pedagógicas precisam ser diferenciadas.

A política de inclusão escolar vigente no Brasil prevê o acesso dos alunos PAEE às classes comuns das escolas regulares com o suporte do Atendimento Educacional Especializado (AEE), que, nas escolas regulares, funciona nas Salas de Recurso Multifuncionais (SRM), em turno inverso ao da classe comum. Esse serviço constitui-se em um conjunto de atividades, recursos de acessibilidade e pedagógicos, organizados institucionalmente, prestados de forma complementar à formação de estudantes com deficiência e transtornos globais do desenvolvimento; e suplementar à formação de estudantes com altas habilidades/superdotação (BRASIL, 2011).

Há muita discussão em torno do AEE, pois não são muito claras as suas funções, embora seja definido como um suporte pedagógico ao trabalho do professor da classe comum. Os documentos normativos veiculam a ideia de que o trabalho no AEE não está vinculado ao currículo, deixando claro o fato de ser a classe comum o lócus da aprendizagem. Entretanto, o trabalho do professor especialista não pode estar totalmente desvinculado do currículo.

Mendes, Tannús-Valadão e Milanesi (2016) realizaram um estudo com o objetivo de descrever e analisar como os alunos com DI têm sido ensinados no contexto do AEE por professores de SRM, considerados especialistas. O estudo foi conduzido em 56 municípios e a síntese da análise dos dados resultou na identificação de oito diferentes tendências curriculares encontradas em discursos de professores do AEE para estudantes com DI e que se referem a ênfases dadas no ensino de diferentes conteúdos, a saber:

Autonomia (atividades de vida diária), 2) Motivação (atividades lúdicas e de lazer), 3) Instrumentação (uso de recursos tecnológicos), 4) Currículo padrão (reforço do conteúdo acadêmico da classe comum), 5) Currículo adaptado (conteúdo acadêmico simplificado), 6) Prontidão ou preparação (ênfase em atividades psicomotoras), 7) Letramento e alfabetização (leitura e escrita) e, 8) Compensatório (treino em habilidades cognitivas superiores para o impedimento intelectual) (MENDES; TANNÙS-VALADÃO; MILANESI, 2016, p. 45).

Diante desses resultados, as pesquisadoras identificaram a presença de tendências que parecem inovadoras no campo da escolarização de estudantes com DI, como as que fazem referência ao currículo (padrão ou adaptado) e a de instrumentação. Elas admitem que tais tendências, priorizando o currículo padrão, podem ser explicadas como consequência da própria prática de inclusão escolar que exige o enquadramento desses alunos na organização escolar vigente, mas também soam como reflexo da falta de definição clara nos documentos orientadores do Ministério de Educação sobre como deve ser o AEE 
para estudantes com DI, pois neles transparece a ideia de que na SRM não devem ser trabalhados os conteúdos curriculares, apenas as "habilidades" necessárias para acessar o currículo.

Esses resultados, de acordo com as autoras, apontam para uma indefinição sobre a quem cabe a responsabilidade pela alfabetização dos alunos com DI e como garantir a eles o acesso ao currículo comum. Esse fato tem consequências drásticas para os alunos com DI, visto que não são alfabetizados nesse contexto, nem nas classes comuns.

A análise das produções científicas a respeito das práticas docentes para com educandos com DI, apontou vários estudos (OLIVEIRA, 2010; MOSCARDINI, 2011; SANTOS, 2012; SILVA, 2013; SILVA-PORTA, 2015; COSTA, 2016), os quais se voltam para a análise da rotina da sala de aula, de aspectos relacionais, intervenções pedagógicas, metodologias e estratégias de ensino, formação do professor, dentre outros. O panorama das pesquisas apresentadas revela que, em relação às práticas docentes direcionadas aos alunos com DI nas escolas regulares, temos muito que avançar.

Os problemas são vários e recorrentes e se repetiram em todas as pesquisas analisadas e evidenciam a precária formação do professor, o distanciamento entre o professor do ensino regular e o professor especializado, as práticas pedagógicas tradicionais, inadequadas para o contexto inclusivo, a ausência de recursos e estratégias de acessibilidade ao currículo etc. Tudo isso leva ao gravíssimo problema de a escola não possibilitar o acesso do aluno PAEE, notadamente do que apresenta DI, aos saberes escolares, pois os professores não desenvolvem práticas capazes de contemplar a diversidade presente na sala de aula e continuam presos a uma abordagem centrada no aluno, perspectiva a partir da qual, o problema centra-se no educando e não no contexto e na própria prática.

\section{METODOLOGIA}

Para a realização desse estudo, fizemos opção pela abordagem qualitativa, alicerçada nos fundamentos da pesquisa-ação, justificando a pertinência metodológica dessa abordagem por considerar que ela traz um potencial para auxiliar tanto nas reflexões quanto na construção de conhecimentos sobre os processos escolares. Sua pertinência aos estudos na área educacional, particularmente na área de Educação Especial relacionada a questões sobre a inclusão, é atestada pela possibilidade real de mudança no contexto escolar, na medida em que todos os envolvidos são afetados no processo de reflexão e ação sobre suas concepções e práticas (BRAUN, 2014).

A pesquisa foi desenvolvida em duas escolas da rede municipal de ensino de Teresina - PI. A escolha das escolas foi feita a partir de um mapeamento fornecido pela Divisão de Educação Inclusiva (DEI) da Secretaria Municipal de Educação e Cultura de Teresina (SEMEC), contendo as escolas que atendiam alunos com DI. As escolas foram denominadas, então, com vistas a preservar o anonimato, de Escola A e de Escola B. A seleção das 
escolas levou em conta o interesse dos professores, suas queixas quanto às dificuldades enfrentadas com esse alunado e a disponibilidade de horário para participar do processo formativo/investigativo.

Participaram desse estudo seis professoras que trabalhavam nas escolas selecionadas como professoras efetivas, atuando com alunos com DI, nos anos iniciais do ensino fundamental. A escolha das participantes foi feita a partir dos seguintes critérios: 1) ser professora efetiva do quadro permanente do município; 2) trabalhar nos anos iniciais do ensino fundamental, atuando na classe comum; 3) estar trabalhando com aluno com DI; 4) ter experiência mínima de dois anos com esse público; 5) relatar sentir-se desafiada pelo trabalho que realiza; 6) ter interesse pelo estudo e disponibilidade de horário para participar dos encontros.

O grupo ficou constituído por duas professoras da Escola A (uma do terceiro e outra do quarto ano) e quatro professoras da Escola B (duas do primeiro, uma do quarto e duas do quinto ano). Os nomes das participantes foram substituídos com o fim de preservar suas identidades. O nome adotado foi escolhido pelas interlocutoras, ficando assim nomeadas: Abigail, Júlia, Olívia, Valentina, Ana e Bárbara. No caso das Escolas, quando especificadas pelas professoras, as pesquisadoras optaram por excluir o nome, indicando apenas que se tratava de escola pública ou privada. Os alunos com DI, quando mencionados pelas professoras, foram nomeados com a letra inicial do nome.

A idade das professoras variam entre 26 e 51 anos. Quanto ao estado civil, três eram solteiras, duas casadas e uma divorciada. Todas tinham formação em Pedagogia, assim como especialização, de modo que três delas eram especialistas em Psicopedagogia, e as outras, em áreas diversificadas, com, por exemplo, Gestão. As participantes têm entre seis e quinze anos de trabalho como docentes, bem como alguma experiência com alunos PAEE, e no ano da pesquisa tinham alunos com DI na sala de aula, conforme estabeleciam os critérios de inclusão da pesquisa. A experiência docente de quatro participantes era somente na escola pública e duas tinham experiência em escola pública e privada.

Para a concretização dessa pesquisa, adotamos três procedimentos que julgamos pertinentes aos propósitos desse estudo, quais sejam: diagnóstico dos conhecimentos prévios das participantes e sugestões de temas para o processo formativo; sessões de estudo que denominamos "Encontros de Estudo e Observação". Cada procedimento requereu tipos diferenciados de instrumento para produção das informações.

Desse modo, para fazer o diagnóstico das temáticas de interesse, aplicamos um Questionário com questões fechadas sobre características sociodemográficas das professoras, seus conhecimentos prévios acerca de alunos com DI, sugestões de temas a serem desenvolvidos no curso de formação, entre outros aspectos.

No âmbito dessa pesquisa, realizamos dez Encontros de Estudo nos quais foram feitos o levantamento dos conhecimentos prévios, leitura e discussão de textos, avaliação do trabalho realizado e análise da prática das professoras, a partir dos Casos de En- 
sino. Os encontros destinados à análise da prática docente, a partir dos casos de ensino, foram gravados e, posteriormente, transcritos.

Os Casos de Ensino são considerados valiosos nos processos formativos, pois permitem o desenvolvimento de processos reflexivos, constituindo-se, ao mesmo tempo, em ferramenta de formação e investigação. O interesse por esses instrumentos surgiu na década de 1980, quando autores como Shulman e Merseth apontaram a importância dessa metodologia de ensino e pesquisa nos processos de formação de professores (NONO; MIZUKAMI, 2002). Os Casos de Ensino são definidos como:

[...] documentos que abordam situações reais, vivenciadas em contexto escolar específico, e se apresentam na forma de registros escritos com a exposição de um evento ou episódio de ensino. Apresentam início, meio e fim, podendo incluir, ainda, uma situação dramática a ser aliviada, revelando o trabalho de mãos, mentes, motivos, concepções, necessidades, frustrações e falhas humanas. Constituem um retrato de uma situação-problema enfrentada por um professor, as diversas abordagens que poderiam ter sido adotadas e algumas informações sobre como conseguiu lidar com a situação dilemática (DUEK, 2014, p. 26).

O trabalho com os Casos de Ensino aconteceu em duas etapas. Inicialmente as professoras analisaram três casos selecionados na literatura, envolvendo temáticas relativas à inclusão de alunos com DI, abordando dificuldades enfrentadas e intervenção pedagógica. Os casos analisados foram: "Trajetória profissional de Adriana: o desafio de desenvolver uma prática inclusiva" (LUSTOSA; FREIRE, 2007 apud DUEK, 2011); "E agora? O que vou fazer?", e "Do conhecimento do aluno à sua inclusão" (DUEK, 2006 apud DUEK, 2011). As análises dos casos foram feitas individualmente a partir de roteiros de questões abertas fornecidos às participantes e, posteriormente, discutidas no grupo.

Na segunda etapa, as professoras elaboraram o seu próprio Caso de Ensino a partir de suas experiências com alunos com DI. Para tanto, foi disponibilizado um roteiro com orientações para a construção dos relatos pelas professoras, os quais foram discutidos posteriormente em dois encontros. Na discussão, as professoras explicitaram o motivo da escolha da situação relatada.

Nesta pesquisa, as Observações seguiram um roteiro pré-estabelecido com registro no Diário de Campo. Nesse sentido, foram observadas as aulas das participantes, nos turnos em que o aluno com DI frequentava, de modo que duraram toda a manhã ou toda a tarde. Foram observadas três aulas de cada professora, ou seja, ao todo, foram realizadas dezoito observações. As aulas observadas foram registradas de forma descritiva durante a observação, e, imediatamente, registradas as considerações da pesquisadora, as quais possibilitaram as reflexões e discussões implementadas nos encontros de estudo quando da análise dos Casos de Ensino. 
Para a análise dos dados produzidos, foram consideradas as informações provenientes do questionário de sondagem, dos questionários respondidos individualmente sobre cada Caso de Ensino analisado, dos casos de ensino elaborados por cada participante, dos depoimentos das professoras nas discussões coletivas sobre os casos de ensino, durante os Encontros de Estudo e dos registros das observações feitos no diário de campo.

Para a organização das informações, partimos da nossa problematização inicial e dos nossos objetivos para nortear a definição das categorias de análise, a partir da Análise de Conteúdo (BARDIN, 2011; FRANCO, 2008). Desse modo, após essa organização e considerando os objetivos do estudo, as falas das participantes e o que aponta a literatura sobre o tema foram definidas duas categorias de análise, a saber: A prática docente e deficiência intelectual e Dificuldades na prática docente. As outras categorias não serão discutidas nesse artigo.

\section{ANÁLISE E DISCUSSÃO DOS RESULTADOS}

Levando em conta os objetivos da pesquisa, as informações produzidas foram organizadas nas categorias A prática docente e a deficiência intelectual e Dificuldades enfrentadas na prática docente, privilegiando-se em cada uma a descrição de episódios significativos emergentes nas ações desenvolvidas.

\section{1) A PRÁTICA DOCENTE E DEFICIÊNCIA INTELECTUAL}

No caso específico desse estudo, o nosso olhar se dirigiu aos alunos com DI inseridos nas salas das professoras participantes. Interessava-nos saber como eram ensinados a esses alunos os conteúdos pedagógicos, quais ações eram desenvolvidas em sala de aula no esforço para que esses alunos se apropriassem desses conteúdos, para que tivessem acesso ao currículo escolar. Assim, foram sistematizadas nessa categoria excertos ou comentários das participantes que relatassem ou descrevessem ações por elas desenvolvidas na sala de aula com o aluno com deficiência intelectual.

Entendemos que a prática docente se refere à atividade do professor no contexto da sala de aula e é definida pelos seguintes elementos: a visão da prática pelo próprio professor, a organização do currículo (o que, como e quando ensinar e avaliar), estratégias pedagógicas adotadas pelos docentes, a promoção e retenção do educando. A partir desse entendimento, elegemos dois desses elementos definidores da prática docente: a organização do currículo e as estratégias pedagógicas adotados pelas docentes e as subcategorias a partir das quais organizamos e discutimos as informações que produzimos.

Na subcategoria organização do currículo, discutimos como as participantes procuram equacionar questões sobre como, quando e o que ensinar, ou seja, como elas organizam o currículo pensando nos alunos com DI que estão em suas salas. Quando solicita- 
das a falar sobre o trabalho pedagógico que realizam com conteúdo específico de alguma área do conhecimento e como envolvem os alunos com DI, as professoras demonstraram muita dificuldade, deixando transparecer que esses alunos não têm acesso ao currículo comum que é trabalhado com seus colegas na sala de aula.

As informações fornecidas pelas professoras indicam que elas utilizam com os alunos com DI atividades distanciadas do currículo trabalhado com a turma, mais simples e mais fáceis, conforme relatam as professoras Júlia, Olívia e Abigail:

\footnotetext{
Em atividade com conteúdo mais simples, como Artes e Educação Física dá para trabalhar com todos, a Matemática também dá, mas Língua Portuguesa não dá para trabalhar com todos os alunos. Então é assim: algum conteúdo dá para trabalhar com eles, outros, não. (Profa. Julia.)

As que eu trabalho com a MC não são atividades com os conteúdos programáticos trabalhados no $5^{\circ}$ ano. São atividades diferenciadas porque ela não acompanha. São outros conteúdos (Profa. Olívia).

Ainda não consegui desenvolver atividades que incluíssem todos. E que todos conseguissem aprender determinados conteúdos (Profa. Abigail).
}

Percebemos uma ênfase das professoras no trabalho com Artes e Educação Física por considerarem que é o único trabalho possível e que desperta o interesse desses alunos, resultando numa situação em que eles não conseguem se alfabetizar. Nas falas das professoras Abigail, Júlia e Bárbara há ênfase nas atividades de desenho e pintura, conforme os relatos a seguir:

Eles conseguem desenhar, pintar, dançar. Desenvolver uma atividade com eles nessas áreas não tem problema. A dificuldade está nas outras áreas, principalmente no que diz respeito à escrita e leitura (Profa. Abigail).

A gente trabalha a coordenação motora através da pintura, recorte e colagem (Profa. Julia).

Se for desenho e pintura eles até participam, se sentem bem. Agora na hora do conteúdo, de aprender, eles não querem fazer, não gostam de fazer, se zangam. O que eu tenho feito é pegar tarefas mais fáceis que acho que eles conseguem responder, tenho trabalhado a questão da arte com eles (Profa. Bárbara).

O discurso dessas professoras corrobora os achados de Pletsch (2014), que, ao investigar o processo de ensino aprendizagem de um aluno com DI na escola regular, constatou que a ele eram oferecidas atividades que proporcionavam apenasconhecimentos elementares. Capellini e Rodrigues (2009) alertam para o fato de que essa prática de usar desenho e pintura para os alunos PAEE, enquanto os demais realizam outras atividades, adotada por muitos professores, pode ter um efeito negativo sobre esses alunos, fazendoos perder o interesse pelo ensino.

A exceção, no caso desse estudo, está com as professoras Valentina, que sugere trabalhar o mesmo currículo, muito embora não detalhe sua forma de trabalho, e a profes- 
sora Ana, que, ainda que diga que faz um trabalho diferenciado, deixa transparecer que o conteúdo é o mesmo. Valentina trabalha o mesmo conteúdo e as mesmas estratégias, diferenciando o modo de avaliar, segundo seu relato:

\begin{abstract}
Quanto ao conteúdo do $5^{\circ}$ ano, a N. e o D. conseguem acompanhar um pouco, dentro das limitações deles, conseguem acompanhar, mas os outros dois não conseguem fazer nada. No caso do D. e da N. que já têm alguma evolução, eu procuro desafiá-los, eu dou as mesmas atividades e avalio naquilo que eles fazem de meIhor. Tem 22 questões em um simulado, a N. vai lá, lê, compreende o que lê e acerta oito. Para mim essa evolução é maravilhosa e faço questão de dizer para a turma que ela acertou oito. Eu costumo querer motivar, desafiar cada vez mais naquilo que ela já consegue.
\end{abstract}

Já Ana relata que o trabalho é feito com estratégias diferenciadas, mas que não parecem favorecer a aprendizagem.

Procuro fazer um trabalho diferenciado, é complicado. Muitas vezes, dependendo do conteúdo que estou trabalhando, considerando as habilidades que estão postas para ser alcançadas, eu procuro ficar perto, sempre ficar direcionando, instigando o aluno para que faça a atividade.

Podemos identificar, nas falas das professoras, em relação à forma como organizam o currículo, duas das tendências curriculares identificadas por Mendes, Tannus-Valadão e Milanesi (2016), ao realizarem um estudo sobre essa questão. A tendência denominada "Ensino de Currículo Adaptado (CA)", em que o professor enfatiza ou prioriza o ensino do currículo com adequações, adaptações ou ajustes do conteúdo nas atividades e com recursos pedagógicos diferenciados ou diferenciando as estratégias de ensino, aparece nos relatos das professoras Olívia e Ana.

Nas falas das professoras Abigail, Julia e Bárbara, podemos identificar a tendência denominada "Treino de prontidão ou preparação (PP)", que se manifesta quando os professores dizem enfatizar ou priorizar o ensino de habilidades para preparar o aluno para a alfabetização, como as atividades psicomotoras (recorte, pintura, colagem) para desenvolvimento da coordenação motora.

Na subcategoria Estratégias pedagógicas adotados pelas docentes, entendidas como os procedimentos que o professor planeja e executa para atingir os objetivos de ensino, abrigamos todas as informações relativas a como as professoras ensinam os alunos com DI, quais os procedimentos utilizados. Interrogadas sobre essa questão, as professoras informaram o seguinte:

Tento adaptar os conteúdos à suas limitações. Procuro incluir o aluno em atividades como ajudante do dia, em histórias e brincadeiras mesmo que o aluno não consiga 
completar suas tarefas na brincadeira [...] uma atividade que costumo fazer é Troca-letras (Profa. Julia).

Utilizo diversas técnicas. Tudo é de acordo com a necessidade das crianças. Utilizo bingo de palavras, desenho e pintura dirigido, atividades adaptadas para o nível de aprendizagem. Tive uma criança com Síndrome de Down em nível avançado, ou seja, ele não tinha só a síndrome. Trabalhei um conteúdo de Artes, cores (Profa. Abigail).

Gosto muito de trabalhar com afetividade e atividades artísticas, tais como: teatro, música, pintura e desenho (Profa. Bárbara).

Atividades diferenciadas como jogos educativos, duplas produtivas e brincadeiras em que o aluno possa se sentir como parte integrante da turma (Profa. Valentina). O trabalho com duplas produtivas; a utilização de material concreto como alfabeto móvel, cartelas, jogos de alfabetização do Plano Nacional de Alfabetização na Idade Certa - PNAIC e a aproximação da carteira do aluno à frente, bem próximo à mesa do professor (Profa. Ana).

É possível perceber que as professoras, às vezes, tentam e fazem como podem. Quando não conseguem, trazem tarefas diferentes (simplificadas do currículo da educação infantil) e fazem modificações curriculares. Não são diferenciações. Devemos considerar também que, às vezes, elas adotam algumas estratégias universais para a participação de todos. Tudo é muito variável, depende das demandas da tarefa, do desempenho dos alunos da turma, do aluno com DI e do conhecimento e repertório de diversificação que elas têm para ensinar determinado conteúdo.

O ideal seria que as professoras trabalhassem em regime de colaboração (MENDES; VILARONGA; ZERBATO, 2014) com o professor especialista, aprofundando o conhecimento acerca do aluno, seja a partir da observação de suas condições concretas, seja na parceria constante com as famílias, de modo a atuar na zona de desenvolvimento próximal (VIGOSTKI, 1991), fundamentadas em um Plano Educacional Individualizado (SIQUEIRA; MASCARO; VIANNA; SILVA; REDIG, 2012; TANNÚS-VALADÃO, 2014) desenvolvido em função dessas parcerias e respaldadas por um Projeto Político Pedagógico que acentue a importância do contexto social.

Durante as observações, o que podemos constatar foi que, em alguns momentos, os alunos com DI têm acesso ao currículo trabalhado com a turma, mas isso não é sistemático e as professoras desconhecem como lidar com as diferenças deles no ensino da turma, uma vez que pensam sempre que tem que ser realizado algo de modo paralelo, fato que pode ser constatado através dos trechos transcritos, extraídos do diário de campo, referentes às observações feitas em sala de aula.

Turma do $3^{\circ}$ ano, com o aluno $\mathrm{G}$ incluído. A professora informa que a aula é de Língua Portuguesa [...]A atividade seguinte foi a interpretação de um texto. A professora distribuiu uma folha para cada aluno contendo um texto, questões de compreensão do texto e questões de gramática: comparativo e grafia L/U. O G. recebe uma atividade diferenciada. A professora lhe entrega uma folha com alguns desenhos 
e solicita que escreva as palavras correspondentes às figuras. G. tenta escrever e vem me mostrar [...] (Diário de campo em 12/09/2017, aula da professora Julia).

Turma do $5^{\circ}$ ano com a aluna MC incluída. A professora organiza a turma e informa que vai ter uma revisão de Matemática para a Prova Brasil. A professora inicia sua revisão resolvendo problemas no quadro e os alunos participam da revisão. Paralelamente, a PA dá aula para MC. Ela dá orientações para a realização de uma atividade de recorte e colagem. Fala alto, concorrendo com a professora [...] (Diário de campo em 03/10/2017, aula da professora Olívia).

O que podemos concluir a respeito dos resultados encontrados em relação ao currículo para alunos com DI, especialmente quanto à organização curricular e às estratégias pedagógicas a serem utilizadas para possibilitar o acesso ao currículo, é que as professoras têm poucas informações a esse respeito, parecem ainda não compreender que a escolarização desses alunos deve ocorrer na classe comum, uma vez que esse é o espaço no qual o currículo há que ser consolidado, e ao professor cabe a tarefa de encontrar formas diferenciadas que possibilitem a esses educandos os mesmos benefícios disponibilizados para os demais (OLIVEIRA, BRAUN, LARA, 2013). Devemos, porém, ressaltar que a responsabilidade por decisões relacionadas a questões curriculares não pode ser exclusiva do professor, pois este precisa do apoio da equipe gestora da escola.

\section{2) DIFICULDADES ENFRENTADAS NA PRÁTICA DOCENTE}

A escolarização de alunos com DI tem encontrado vários obstáculos no cotidiano e essa foi uma questão muito evidenciada nos casos de ensino analisados. Assim, essa categoria trata das dificuldades vividas pelas professoras em relação ao processo de ensino e aprendizagem do aluno com DI. A falta de formação específica para trabalhar com alunos PAEE foi o elemento que mais se destacou como dificuldade na fala das professoras, realçado pelo sentimento de despreparo para o trabalho, atribuído em grande parte a uma formação precária e a uma ausência de suporte pedagógico. De diferentes maneiras, cada uma falou sobre a ausência de formação específica para trabalhar com esse alunado.

Explicando a ausência de formação específica, a professora Ana relata que, na graduação em Pedagogia, cursou a disciplina Educação Especial e, posteriormente, fez uma pós-graduação em Psicopedagogia, mas isso não foi suficiente para as demandas que a escola apresenta. A professora Olívia afirmou que, sem uma formação específica, a inclusão nunca será efetivada, pois é esta que fará com que a "inclusão aconteça e, dessa forma, o professor terá um embasamento teórico e segurança em sua prática diante dessa realidade que é tão árdua".

Por esses relatos, entendemos que as professoras atribuem à falta de formação específica a não aprendizagem dos alunos com DI, mas como se justifica o caso dos outros que não aprendem? Fica evidente que elas têm a crença de que o ensino deles deve ser 
bem diferente, que existe alguma coisa mágica ou diferente para fazê-los aprender. Elas pensam que o ensino dos alunos com DI deve ser muito diferenciado dos demais.

Campos e Mendes (2015) questionam o modelo de formação adotado hoje no país, destacando que muitas instituições de ensino superior (IES) não estão preocupadas em formar professores para a inclusão escolar, pois seus estudos indicaram que, na grade curricular de cursos de licenciatura na modalidade a distância, às vezes, aparecia apenas uma disciplina com esse conteúdo, aliado ao fato de que estes eram oferecidos, em sua grande maioria, por instituições privadas, de modo que restaria aos professores que têm interesse pela temática, custearem sua própria formação continuada e em serviço.

Além da falta de formação específica, as professoras apontam outros problemas que, no entendimento delas, também se configuram como obstáculos ao trabalho do professor junto ao PAEE, mais especialmente ao aluno com DI. Esses resultados estão em concordância com os achados de Capellini e Rodrigues (2009), segundo os quais os fatores que mais dificultam a inclusão escolar referem-se aos aspectos escola, professor e família do aluno.

No que se refere à escola, os maiores desafios dizem respeito ao número excessivo de alunos por classe (professora Valentina), à falta de suporte de uma equipe técnica e à falta de materiais adequados (professoras Abigail, Júlia, Ana). Na categoria características do professor, os obstáculos apontados foram: formação continuada insuficiente para o trabalho com a inclusão, práticas pedagógicas inadequadas para lidar com a diferença, formação inicial precária (professoras Júlia, Bárbara, Ana e Olívia). Por fim, na categoria família do aluno, apareceu o descompromisso dos pais como uma grande dificuldade para a inclusão (professoras Abigail e Ana).

O que podemos concluir nessa categoria, com base nos resultados que encontramos, é que as maiores dificuldades apontadas pelas professoras dizem respeito à falta de formação específica para atuar com esse alunado. Nesse sentido, há menção a uma formação inicial insuficiente, bem como à ausência de uma política de formação continuada que possa Ihes ajudar a redimensionar sua ação pedagógica na direção de um trabalho que considere a realidade atual das salas de aula formadas por grupos heterogêneos de alunos.

\section{CONSIDERAÇÕES FINAIS}

A análise das informações decorrentes da pesquisa revelou, em relação à organização do currículo, que as participantes desse estudo demonstraram estar ainda distante da implementação de uma proposta inclusiva, pois, apesar de os alunos com DI estarem inserido nas escolas regulares, não se pode afirmar que suas necessidades de aprendizagem estejam totalmente atendidas. Como os dados mostraram, as professoras confessaram não saber o que fazer com esses educandos, tanto porque elas não sabiam, quanto pelo fato 
deles não estarem alfabetizados e não conseguirem participar das atividades propostas para os demais.

Em relação à prática docente, os dados revelaram dificuldades das professoras em trabalhar um currículo comum nas salas que tinham alunos com DI e uma ênfase das professoras no trabalho com Artes e Educação Física, por considerarem ser o único conteúdo possível e que desperta o interesse desses alunos, resultando numa situação em que, consequentemente, eles não conseguiam se alfabetizar. Quanto à organização do currículo, o que ficou evidente é que nem sempre os alunos conseguiam acessar o currículo comum. As professoras, por sua vez, não conseguiram organizar e implementar práticas diferenciadas da proposta curricular do ano escolar que o aluno estava frequentando.

No que diz respeito às dificuldades enfrentadas na prática docente, a falta de formação específica para trabalhar com alunos PAEE foi o elemento que mais se destacou como dificuldade na fala das professoras, realçado pelo sentimento de despreparo para o trabalho, atribuído em grande parte a uma formação precária e à ausência de suporte pedagógico. As professoras tinham formação inicial em Pedagogia e revelaram que nesse processo formativo tiveram acesso a uma única disciplina da área de Educação Especial. Algumas não chegaram a cursar nenhuma disciplina.

O número excessivo de alunos por classe, a ausência de suporte de uma equipe técnica e a falta de materiais adequados, formação continuada insuficiente para o trabaIho com a inclusão, formação inicial precária e o descompromisso dos pais também foram apontados como dificuldades. Ficou evidenciado que as professoras tendiam a promover os alunos com deficiência intelectual no final do ano, sem nenhum questionamento em relação às habilidades desenvolvidas por eles, motivadas pelas exigências e cobranças da SEMEC por resultados.

O estudo nos possibilitou a compreensão de que, para efetivar o ensino na perspectiva da inclusão, precisamos melhorar o ensino na classe comum e, para isso, temos que enfatizar o apoio na classe comum, focalizar mais as estratégias pedagógicas, adotando práticas que favoreçam a todos. Nesse sentido, entendemos que há necessidade de fortalecer a formação inicial dos professores, incluindo conteúdos referentes a práticas inclusivas, como, por exemplo, o desenho universal, o ensino diferenciado, o ensino colaborativo, dentre outras, pois a ênfase deve recair no ensino para todos e não nos ajustes individuais. 


\section{REFERÊNCIAS}

ALMEIDA, Mariangela Lima de. A prática pedagógica inclusiva: o ensino em multiníveis como possibilidade. In: ALMEIDA, Mariangela Lima de; RAMOS, Ines de Oliveira (Orgs.). Diálogos sobre práticas pedagógicas inclusivas. Curitiba: Appris, 2012, pp. 71-100.

BARDIN, L. Análise de Conteúdo. Lisboa: Edições 70, 2011.

BRASIL. Ministério da Educação. Secretaria de Educação Especial. Decreto $\mathbf{n}^{\circ} 5.296$ de 02 de dezembro de 2004.

BRAUN, Patrícia. Uma intervenção colaborativa sobre os processos de ensino e aprendizagem do aluno com deficiência intelectual. Rio de Janeiro, RJ, 2012. Tese de Doutorado.

BRAUN, Patrícia. A pesquisa-ação: aspectos conceituais, aplicação e implicações em investigações sobre Educação Especial. In: Leila Regina d'Oliveira de Paula Nunes (Org.). Novas trilhas no modo de fazer pesquisa em Educação Especial. São Carlos: Marquezine \& Manzini: ABPEE, 2014, p. 89-103.

CAMPOS, Mariana de Lima Isaac Leandro; MENDES, Enicéia Gonçalves. Formação de professores para a educação inclusiva em cursos à distância: um estudo de campo documental. Revista Cocar, Belém/Pará, Edição Especial, n.1, p. 209-227, 2015.

CAPELLINI, Vera Lúcia Messias Fialho; RODRIGUES, Olga Maria Piazentin Rolim. Concepções de professores acerca dos fatores que dificultam o processo da educação inclusiva. Educação, Porto Alegre, v. 32, n. 3, p. 355-364, set./dez. 2009, pp. 355-364.

CARNEIRO, Maria Sylvia Cardoso. A Deficiência Mental como produção social: de Itard à Abordagem Histórico-Cultural. In: BAPTISTA, Claudio Roberto (Org.). Inclusão e Escolarização. Porto Alegre: Mediação, 2006.

CHINALIA, Fabiana. Perspectivas de inclusão escolar: deficiência intelectual, conhecimento e trabalho pedagógico. In: MONTEIRO, Maria Inês Bacellar; FREITAS, Ana Paula de; CAMARGO, Evani Andreatta Amaral (Orgs.). Relações de ensino na perspectiva inclusiva: alunos e professores no contexto escolar. Araraquara- SP: Junqueira \&Marin, 2014. pp. 111- 133.

COSTA, Maria da Piedade Resende da. Alfabetização para o aluno com Deficiência Intelectual. São Paulo: Edicon, 2011.

COSTA, Raquel Almeida. A prática pedagógica de professoras de uma aluna com deficiência intelectual: desafios e possibilidades no cotidiano de uma escola de ensino fundamental. Uberlândia, MG, 2016. Dissertação de Mestrado.

DORZIAT, Ana. A inclusão escolar de surdos: um olhar sobre o currículo. In: JESUS, Denise Meyrelles de; BAPTISTA, Claudio Roberto; BARRETO, Maria Aparecida Santos Côrrea; VICTOR, Sonia Lopes (org.). Inclusão: práticas pedagógicas e trajetórias de pesquisa. Porto Alegre: Mediação, 2007, pp. 54-62. 
DUEK, Viviane Preichardt. Formação Continuada: análise dos recursos e estratégias de ensino para a educação inclusiva sob a ótica docente. Educação em Revista. Belo Horizonte, v. 30, n.02, p.17-42|abril-junho 2014.

DUEK, Viviane Preichardt. Docência e inclusão: reflexões sobre a experiência de ser professor no contexto da escola inclusiva. Dissertação de Mestrado Goiânia (GO), 2006.

DUEK, Viviane Preichardt Educação Inclusiva e formação continuada: contribuição dos casos de ensino para os processos de aprendizagem e desenvolvimento profissional dos professores. Natal, RN, 2011. Tese de Doutorado.

FERREIRA, Maria Cecília Carareto. A educação escolar de alunos com deficiência intelectual pode se viabilizar na perspectiva do letramento? In: JESUS, Denise Meyrelles; BAPTISTA, Claudio Roberto; BARRETO, Maria Aparecida S. Côrrea Barreto; VICTOR, Sonia Lopes. Inclusão: práticas pedagógicas e trajetórias de pesquisa. Porto Alegre: Mediação, 2007, p. 101-109.

FRANCO, Maria Amélia do Rosário Santoro. Pedagogia e prática docente. São Paulo: Cortez, 2012.

FRANCO, Maria Amélia do Rosário Santoro Pedagogia da pesquisa-ação. Educação e Pesquisa, São Paulo, v. 31, n. 3, p. 483-502, set/dez.2005.

FANCO, Maria Laura P. B. Análise de conteúdo. Brasília: Líber Livro Editora, 2008

GARCIA, Rosalba Maria Cardoso. O conceito de flexibilidade curricular nas políticas públicas de inclusão educacional. In: In: JESUS, Denise Meyrelles de; BAPTISTA, Claudio Roberto; BARRETO, Maria Aparecida Santos Côrrea; VICTOR, Sonia Lopes (org.).

Inclusão: práticas pedagógicas e trajetórias de pesquisa. Porto Alegre: Mediação, 2007, pp. 11-20.

GESSER, Marivete; NUERNBERG, Adriano Henrique; TONELI, Maria Juracy Filgueiras. A contribuição do modelo social da deficiência à Psicologia Social. Psicologia \& Sociedade; 24(3): 2012, p. 557-566.

GOULART, Aurea Maria Paes Leme. Adaptação/Flexibilização Curricular. In: MARQUEZINE, Maria Cristina; BUSTO, Rosângela Marques; FUJISAWA, Dirce Shizuko (Org.). Reflexões, Experiências e Práticas sobre Inclusão. São Carlos: ABPEE, Marquezine \& Manzini, 2014, pp. 57-70.

GUAdAGNINI, Larissa; DUARTE, Márcia. Práticas Pedagógicas de Acessibilidade Curricular para Alunos com Deficiência Intelectual em classes do ensino fundamental e médio. VII Congresso Brasileiro de Educação Especial. Londrinas, 2013.

HEACOX, Diane. Diferenciação curricular na sala de aula: como efectuar alterações curriculares para todos os alunos. Porto, Portugal: Porto Editora, 2006.

LIMA, Rita Carla; SÉRGIO, Maria Cândida; SOUZA, Adriana Cristina de. A Prática docente do professor da educação infantil: contribuições para o desenvolvimento das crianças. Revista e-curriculum, São Paulo, v.8 n.1 ABRIL 2012. Disponível em: http://revistas.pucsp.br/index.php/curriculum. Acesso em: 15/06/2018. 
LUSTOSA, F. G.; FREIRE, A. M. Bem-vindos à inclusão: relatos de uma professora sobre a experiência de receber alunos com deficiência no sistema regular de ensino. In: ENCONTRO DE PESQUISA EDUCACIONAL DO NORTE E NORDESTE, 18, 2007 Maceió.

Anais...Maceió: EPENN, 2007, p. 1 - 13.

MAZZOTA, Marcos J. S. Educação Especial no Brasil: história e políticas públicas. São Paulo: Cortez, 1996.

MENDES, Enicéia Gonçalves. Deficiência mental: a construção científica de um conceito e a realidade educacional. 1995. Tese (Doutorado em Psicologia) - Universidade de São Paulo, São Paulo, 1995.

MENDES, Enicéia Gonçalves; VILARONGA, Carla Ariela Rios; ZERBATO, Ana Paula. Ensino Colaborativo como apoio à inclusão escolar: unindo esforços entre educação comum e especial. São Carlos: EDUFSCar. 2014.

MENDES, Enicéia Gonçalves; TANNÚS-VALADÃO, Gabriela; MILANESI, Josiane Beltrame. Atendimento Educacional Especializado para estudante com deficiência intelectual: os diferentes discursos dos professores especializados sobre o que e como ensinar. Revista Linhas. Florianópolis, v. 17, n. 35, p. 45-67, set./dez. 2016.

MOSCARDINI, Saulo Fantato. Escolarização de alunos com deficiência intelectual em classes comuns e em Salas de Recursos Multifuncionais, 2011. Dissertação de Mestrado. Programa de Pós-Graduação em Educação Escolar da Faculdade de Ciências e Letras UNESP/Araraquara. Orientadora Silvia Regina Ricco Lucato Sigolo.

NONO, Maévi Anabel; MIZUKAMI, Maria da Graça Nicoletti. Casos de ensino e processos de aprendizagem profissional docente. R. bras. Est. pedag. Brasília, v. 83, n. 203/204/205, p. 72-84, jan. I dez. 2002.

OLIVEIRA, Glaucimara Pires. Intervenção pedagógica individualizada para alunos com deficiência intelectual: ensino de leitura em salas de recursos. São Carlos, 2010. Tese de Doutorado. PICCOLO, Gustavo Martins. Por um pensar sociológico sobre a deficiência. Curitiba: Appris, 2015.

PICCOLO, Gustavo Martins; MENDES, Enicéia Gonçalves. Para além do natural: contribuições sociológicas a um pensar sobre a deficiência. In: MENDES, Enicéia Gonçalves; ALMEIDA, Maria Amélia (org.). A pesquisa sobre inclusão escolar em suas múltiplas dimensões: teoria, política e formação. Marília: ABPEE, 2012, p. 53-90.

PLETSCH, Márcia Denise. Repensando a inclusão escolar de pessoas com deficiência mental: diretrizes políticas, currículo e práticas pedagógicas. 2009. Tese de Doutorado. Programa de Pós-Graduação em Educação - Universidade do Estado do Rio de Janeiro, Orientadora: Rosana Glat.

PLETSCH, Márcia Denise. Notas sobre o desenvolvimento e a aprendizagem de pessoas com deficiência mental/intelectual: o caso de inclusão do aluno Maciel. In: MARQUEZINE, Maria Cristina; BUSTO, Rosângela Marques; FUJISAWA, Dirce Shizuko (Org.). Reflexões, Experiências e Práticas sobre inclusão. São Carlos: ABPEE: Marquezine\& Manzini, 2014, pp 43-56. 
PLETSCH, Marcia Denise; GLAT, Roxana. A escolarização de alunos com deficiência intelectual: uma análise da aplicação do Plano de Desenvolvimento Educacional Individualizado. Linhas Críticas, Brasília, DF, v. 18, n. 35, p. 193-208, jan./abr. 2012 pp. 193- 207.

PLETSCH, Márcia Denise; SOUZA, Flávia Faissal de; ORLEANS,Luis Fernando. A diferenciação curricular e o desenho universal na aprendizagem como princípios para a inclusão escolar. Revista Educação e Cultura Contemporânea, Vol. 14, № 35 (2017)

RICHARDSON, Roberto Jarry. Como fazer pesquisa-ação? In: RICHARDSON, Roberto Jarry (Org.). Pesquisa-Ação: princípios e métodos. João Pessoa: Editora Universitária/UFPB, 2003, p. 149-174.

ROCHA, Maíra Gomes de Souza da; AVILA, Leila Lopes de. Pesquisas, práticas e experiências sobre os processos de ensino e aprendizagem de alunos com deficiência intelectual e múltipla em escolas públicas da Baixada Fluminense. In: PLETSCH, Márcia Denise; MENDES, Geovana Mendonça Lunardi; HOSTIN, Regina Célia Linhares (org.). A escolarização de alunos com deficiência intelectual: políticas, práticas e processos cognitivos. São Carlos: Marquezine\& Manzini: ABPEE, 2015, pp.31-44.

RODRIGUES, Suellen da Rocha; FERNANDES, Edccléa Mascarenhas; ORRICO, Helio Ferreira; ALBUQUERQUE, Caroline da Silvan; MACHADO, Gabriela Rivas. Acessibilidade ao currículo e práticas pedagógicas. In: MARQUEZINE, Maria Cristina; BUSTO, Rosângela Marques; FUJISAWA, Dirce Shizuko (org.). Reflexões, Experiências e Práticas sobre Inclusão. São Carlos: ABPEE, Marquezine\& Manzini, 2014, pp.101-112.

SANDIN ESTEBAN, Maria Paz. Pesquisa Qualitativa em educação: fundamentos e tradições. Porto Alegre: AMGH, 2010.

SANTOS, Ana Lucia Félix dos; AZEVEDO, Janete Maria Lins de. A pós-graduação no Brasil, a pesquisa em educação e os estudos sobre a política educacional: os contornos da constituição de um campo acadêmico. Revista Brasileira de Educação. v 14. N. 42. set.

/dez. 2009.

SANTOS, Teresa Cristina Coelho dos. Educação inclusiva: práticas de professores frente à Deficiência Intelectual, 2012. Dissertação de Mestrado. Programa de Pós-Graduação em Educação -Universidade Federal do Rio Grande do Norte, Orientadora: Lucia de Araújo Barros Martins.

SANTOS, Geandra Claudia Silva. Os impactos dos alunos com desenvolvimento atípico na subjetividade do professor e a configuração do trabalho pedagógico. Brasília-DF, 2010.

Tese de Doutorado.

SASSAKI, Romeu Kazumi. Deficiência Intelectual e Inclusão. Revista Nacional de Reabilitação, ano X, n. 54 (p. 8-11, jan./fev.2007). Disponível em: http://www.planetaeducacao.com.br/portal/artigo.asp?artigo=1320. Acesso em: 06/07/2016.

SILVA, Esther Giacomimi. Formulação de um Programa de Ensino Individualizado (PEI) para o Ensino Inclusivo. In: MANZINI, Eduardo José (Org.). Educação Especial e Inclusão: temas atuais. São Carlos: Marquezine e Manzini Editora, ABPEE, 2013. 
SILVA-PORTA, Wilma Carin. Prática pedagógica aos educandos com deficiência intelectual numa escola de ensino fundamental com alto ideb. São Carlos, SP, 2015. Dissertação de Mestrado.

SIQUEIRA, Carla Fernanda Oliveira de et al. Planos de ensino individualizados na escolarização de alunos com deficiência intelectual. VI Congresso Brasileiro de Educação Especial. São Carlos: novembro de 2012. Disponível em: http://www.eduinclusivapesq- uerj.pro.br/images/pdf/ Carla.Ufscar.2012.pdf. Acesso em: 08/07/ 2012.

SOUZA, João Francisco de. Prática pedagógica e formação de professores. Recife: Ed. Universitária da UFPE, 2012.

TACCA, Maria Carmen Vilela Rosa (org.). Aprendizagem e Trabalho pedagógicas.

Campinas, SP: Editora Alínea, 2006.

TANNÚS-VALADÃO, Gabriela. Inclusão Escolar e Planejamento Educacional Individualizado: avaliação de um programa de formação continuada para educadores. São Carlos-SP. Tese de Doutorado, 2014.

TOMLINSON, Carol Ann. Diferenciação pedagógica e diversidade: ensino de alunos em turmas com diferentes níveis de capacidade. Porto, Portugal, Porto Editora, 2008.

VELTRONE, Aline Aparecida. Inclusão escolar do aluno com deficiência intelectual no estado de São Paulo: identificação e caracterização. São Carlos-SP. Tese de Doutorado, 2011.

VIGOTSKI, Lev Semionovitch. A Formação Social da Mente. São Paulo: Martins Fontes, 1991.

ZERBATO, Ana Paula; MENDES, Enicéia Gonçalves. Desenho universal para a aprendizagem como estratégia de inclusão escolar. Educação Unisinos. 22(2):147-155, abril- junho 2018. 